\title{
INTERNAL RADIATION MONITORING OF OCCUPATIONAL STAFF IN NUCLEAR MEDICINE FACILITY
}

\author{
* M.J.Ferdous ${ }^{1}$, Z.Alam ${ }^{2}$, R.K.Khan ${ }^{1}$, S.M.Iqubal ${ }^{3}$, A.Islam ${ }^{1}$, M.A.Rahman ${ }^{2}$ and Aleya Begum ${ }^{1}$ \\ ${ }^{1}$ Health Physics Division, Atomic Energy Centre, Dhaka \\ ${ }^{2}$ Department of Physics, University of Dhaka \\ ${ }^{3}$ National University, Gazipur \\ e-mail: ferdous28@yahoo.com (Corresponding author)
}

\begin{abstract}
Unsealed radioactive sources used in Nuclear Medicine Centers, to diagnose and treat patients, pose significant risks of internal exposure to the occupational staff. This work intends to evaluate the potential risks of internal contamination of occupational staff in Nuclear Medicine facilities. 49 urine samples of 19 occupational staff working in the two busiest nuclear medicine centres, namely Institute of Nuclear Medicine and Ultrasound (INMU) and Centre of Nuclear Medicine and Ultrasound (CNMU) Dhaka, were collected to perform this study. The concentrations of ${ }^{99 \mathrm{~m}} \mathrm{Tc}$ and ${ }^{131} \mathrm{I}$ in urine samples were measured using a High Purity Germanium (HPGe) detector. The radioactivity of ${ }^{99 \mathrm{~m}} \mathrm{Tc}$ and ${ }^{131} \mathrm{I}$ were found to be $8.58 \pm 0.03 \mathrm{Bql}^{-1}$ to $314 \pm 1.92 \mathrm{Bql}^{-1}$ and from $6.47 \pm 0.03 \mathrm{Bql}^{-1}$ to $283 \pm 0.27 \mathrm{Bql}^{-1}$ respectively. The effective doses of occupational staff have also been calculated using the radioactivity concentration and the dose coefficients. Due to the highest (314 $\left.\mathrm{Bql}^{-1}\right)$ and the lowest $\left(8.58 \mathrm{Bql}^{-1}\right)$ concentration of ${ }^{99 \mathrm{~m}} \mathrm{Tc}$, the effective doses were $14.7 \mu \mathrm{Sv}$ and $0.402 \mu \mathrm{Sv}$, on the other hand for the highest $\left(283 \mathrm{Bql}^{-1}\right)$ and the lowest $\left(6.47 \mathrm{Bql}^{-1}\right)$ concentration of

${ }^{131} \mathrm{I}$, the effective doses were $5.58 \mu \mathrm{Sv}$ and $0.12 \mu \mathrm{Sv}$. These values are within limits, however to avoid inhalation and contamination of ${ }^{131} \mathrm{I}$ and ${ }^{99 \mathrm{~m}} \mathrm{Tc}$ proper working environment should be established with suitable ventilation system, fume hood, mask, etc.
\end{abstract}

\section{INTRODUCTION}

The handling of unsealed sources in nuclear medicine poses significant risks of internal exposure to the occupational staff. Among the most widely used radionuclides in the field of nuclear medicine, ${ }^{99 \mathrm{~m}} \mathrm{Tc}$ and ${ }^{131} \mathrm{I}$ are widely applied for diagnostic and therapeutic purposes. ${ }^{131} \mathrm{I}$ is highly volatile and radiotoxic, which may pose an occupational radiological hazard, especially in places where significant activities are routinely handled. In such situations, staff handling unsealed sources of ${ }^{131}$ I may be internally exposed by inhalation. Though ${ }^{99 \mathrm{~m}} \mathrm{Tc}$ is not as volatile, however it is the most widely used imaging agents in nuclear medicine. Moreover, due to short half life the internal radiation risk that it poses may sometimes be overlooked.

Although it is recognized that in nuclear medicine centers external exposure is usually higher than internal exposure, the risks associated with intakes should be estimated in each case and, if necessary, staff involved in the handling of unsealed sources should be routinely monitored in order to ensure that individual doses are kept as low as possible [1]. Internal monitoring should also be performed in response to an accident or suspected inhalation or ingestion intake.

${ }^{131} \mathrm{I}$ is a short-lived radionuclide (half-life; 8 days). It decays by beta emission producing photons of $0.36 \mathrm{MeV}$. For adults, it is assumed that, of the iodine reaching the blood, $30 \%$ is transported to the thyroid gland and other $70 \%$ is excreted directly in urine via the urinary bladder. The biological halflife in blood is taken to be $6 \mathrm{~h}$. Iodine incorporated into thyroid hormones leaves the gland with biological half-life of 12 days. Most iodine (80\%) is subsequently released and is available in the circulation for uptake by the thyroid or direct urinary excretion; the remainder is excreted via the large intestine in the faeces. Because of the short physical half-life of ${ }^{131} \mathrm{I}$, this recycling is not important in terms of the committed effective dose. Iodine is rapidly absorbed into the circulation following inhalation or ingestion. It is concentrated in the thyroid and excreted predominantly via urine [2].

There are 17 Nuclear Medicine Centers in Bangladesh, from these Centers only two are selected for this study: one is Institute of Nuclear Medicine and Ultrasound (INMU) and another one is Centre of 
Nuclear Medicine and Ultrasound (CNMU) Dhaka. Unsealed radioactive liquid sources such as ${ }^{131} \mathrm{I}$ and ${ }^{99 \mathrm{~m}} \mathrm{Tc}$ are used to diagnose as well as to treat patients in Nuclear Medicine Centers. While processing and labeling of the liquid sources with labeling compounds, the sources may enter the bodies of the occupational staff through inhalation and ingestion. The present work was taken up to measure the contamination of the occupational staff because of the above radiopharmaceuticals.

\section{MATERIALS AND METHODS}

\section{Collection and preparation of samples}

49 urine samples of 19 occupational staff working in the two busiest nuclear medicine centres, namely Institute of Nuclear Medicine and Ultrasound (INMU) and Centre of Nuclear Medicine and Ultrasound (CNMU) Dhaka were collected after 3 to 4 hours of handling of ${ }^{131} \mathrm{I}$ and ${ }^{99 \mathrm{~m}} \mathrm{Tc}$ in standard plastic pots previously identified with name, date and time of collection and activity of handling isotope. Staff were advised to read collecting instructions provided together with the pots. The main concern in this methodology was to reduce the possibility of external contamination of the pots. Samples were processed immediately after collection and measured with the HPGe detector system coupled to a Multichannel Analyzer (MCA) at the Health Physics Division, Atomic Energy Centre, Dhaka under the Bangladesh Atomic Energy Commission. The volumes of the urine samples were measured and were found to be less than $350 \mathrm{ml}$. Finally, the samples were taken in plastic bags and positioned in the HPGe detector to perform the measurement. Due to several reasons such as non availability of radioactive sources, working conditions, etc., it was not possible to collect urine sample periodically.

\section{Radioactivity measurement}

After completion of necessary quality assurance of the HPGe detector the radioactivity of the samples were measured. The liquid nitrogen dewar of the HPGe detector was filled with liquid nitrogen at least 12 hours before the measurement. This allowed sufficient time for cooling of the detector. The detector system was turned 'on' and a 15-minute warm-up period was allowed before the first measurement of each day. The high voltage bias supply to the detector was gradually raised to the operating voltage ( +3200 Volt.), the amplifier coarse gain, fine gain and peak shaping time were also adjusted to the desired values [3]. After all these settings had been done, a period of about half an hour was allowed for stabilization of the system. Then the energy calibration of the detector was checked by placing ${ }^{137} \mathrm{Cs}$ and ${ }^{60} \mathrm{Co}$ point sources at the detector axis with a source-to-detector distance at about $10 \mathrm{~cm}$ for 100 seconds, so that $661.66 \mathrm{keV}, 1170 \mathrm{keV}$, and $1332 \mathrm{keV}$ peaks could appear in the appropriate channels. Then a background spectrum was obtained by placing an empty plastic container on the top of the well-shielded detector head for 3000 seconds. After taking the background reading, each of the sample-filled plastic containers was placed on top of the detector head and then the entrance door to the shielding arrangement was closed. The sample's counts were acquired for 3000 seconds and the spectrum data were preserved in permanent storage devices (floppy and hard disks) of the interfaced computer. The results were printed out on paper after completion of the data acquisition process. The computer software "Silena-Emcaplus version 1.01.2" was used to transform the data of each sample. The analysis sheet contained the energy of emitted gamma photons and the corresponding counts per second including the statistical error, FWHM, etc. After searching for the particular radionuclide's peak and taking the corresponding counts per sec, the total activity for the particular sample was calculated by the following equation,

$$
\mathrm{A}=\mathrm{Net} \mathrm{cps} / \mathrm{p}_{\gamma} \text {. e. } \mathrm{w} \text {......(1) }
$$

Where $\mathrm{A}=$ activity of the radionuclide present in the samples in units of $\mathrm{Bq} \mathrm{l}^{-1}$, cps $=$ counts per sec, $\mathrm{p}_{\gamma}=$ the fraction of a particular gamma-ray energy, e = efficiency of the detector for a particular gamma-ray energy (emitted from the specific radionuclide of interest), $w=$ Quantity (volume) of the sample in litres. 
The mean background reading from a set of measurements was subtracted from each of the sample reading. Every time before carrying an experiment, a number of operations of HPGe detector had to be done, such as (i) energy calibration (ii) energy resolution, (iii) efficiency calibration, and (iv) estimation of lower limit of detection, for each of the detecting radionuclides. During the read out period, the Dewar flask was filled by liquid nitrogen.

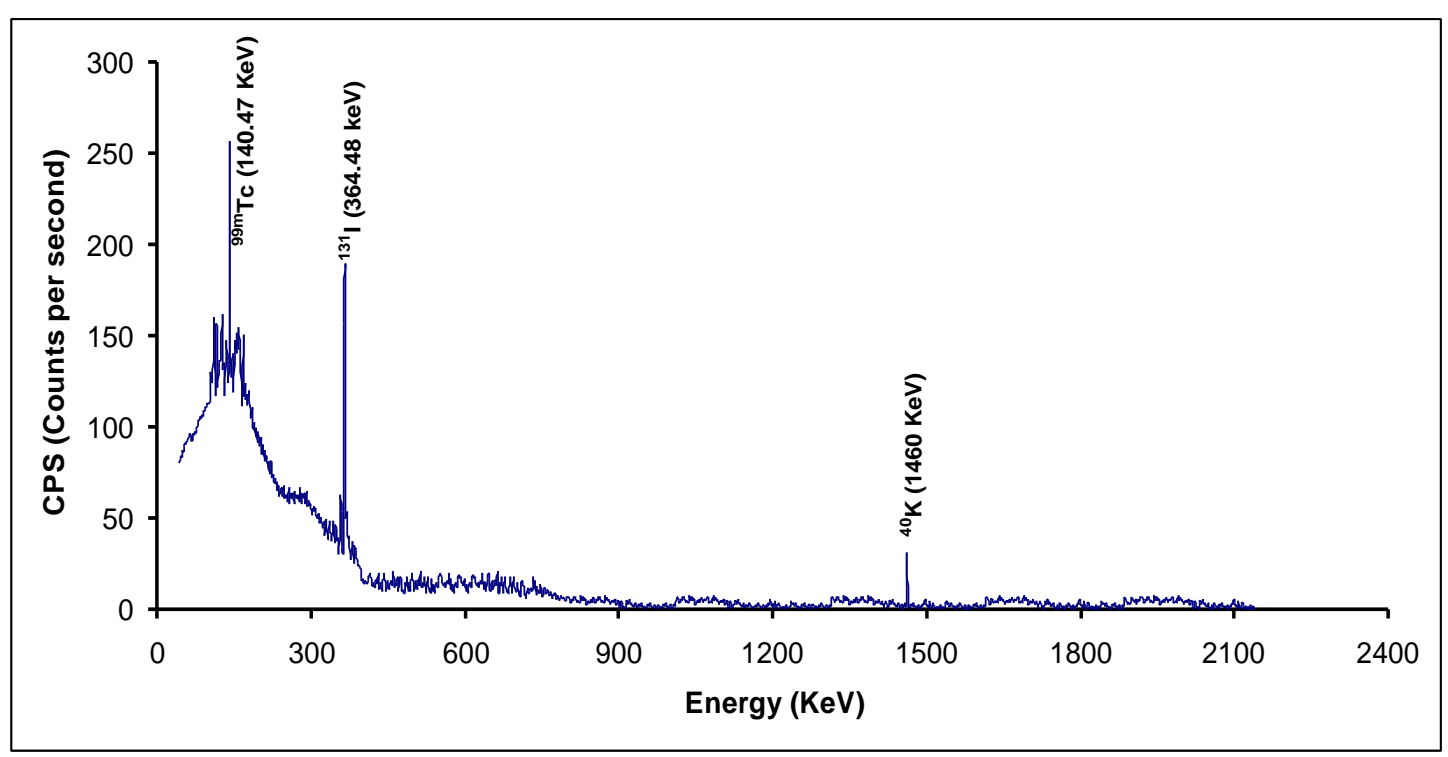

Fig 1: A gamma spectrum of a urine sample

\section{Evaluation of committed effective dose}

The concentration of ${ }^{131} \mathrm{I}$ and ${ }^{99 \mathrm{~m}} \mathrm{Tc}$ radionuclides in the urine samples of the nuclear medicine staff, which were measured with HPGe semiconductor detector, were converted into the concentration per daily urinary volume from which the daily intake and the committed effective dose were evaluated using the following equation [4].

$$
\mathrm{H}_{\mathrm{A}}=\sum \mathrm{I}_{\mathrm{Aj}} \mathrm{h}_{\mathrm{Aj}} \quad \ldots \ldots(2),
$$

where $\mathrm{H}_{\mathrm{A}}$ is the committed effective dose or the committed equivalent dose (Sv) by inhalation for adult, $h_{A j}$ is the inhalation dose coefficient $(\mathrm{Sv} / \mathrm{Bq})$ for the effective dose or for the target organ considered for the radionuclide $j[5]$.

For an acute intake at time $t$ before the measurement, the activity of the radionuclides inhaled can be calculated by

$$
I_{\mathrm{Aj}}=E_{\mathrm{j}} / \mathrm{e}_{\mathrm{aAj}}(\mathrm{t}) \quad \ldots \ldots(3)
$$

where $\mathrm{I}_{\mathrm{Aj}}$ is the activity (in $\mathrm{Bq}$ ) of the radionuclide $j$ inhaled by a member of adult; $\mathrm{E}_{\mathrm{j}}$ is the whole body activity of the radionuclide $j$ or the activity of the radionuclide $j$ in the organ considered, obtained by direct measurement (in $\mathrm{Bq}) ; \mathrm{e}_{\mathrm{aAj}}(\mathrm{t})$ is the fractional activity in total body or in the organ considered at time $\mathrm{t}$ after an acute inhalation ' $\mathrm{a}$ ' of the radionuclide $j$ by a member of age group adult. Values of $\mathrm{e}_{\mathrm{aAj}}(\mathrm{t})$ have been calculated using the biokinetic models and data described in ICRP Publication 78 [6]. 


\section{RESULTS AND DISCUSSION}

As mentioned before 49 urine samples from 19 subjects were studied, and the results are given in Table 1.

Table 1: Radioactivity concentration in urine samples

\begin{tabular}{|c|c|c|}
\hline \multirow{2}{*}{$\begin{array}{l}\text { No. of } \\
\text { urine } \\
\text { samples }\end{array}$} & \multicolumn{2}{|c|}{ Activity \pm Error (in $\left.B q L^{-1}\right)$} \\
\hline & $\begin{array}{c}{ }^{99} \mathrm{~m}_{\mathrm{Tc}} \\
(140.47 \mathrm{Kev})\end{array}$ & $\begin{array}{c}{ }^{131} \mathrm{I} \\
(364.48 \mathrm{Kev})\end{array}$ \\
\hline 1 & $8.58 \pm 0.03$ & $9.48 \pm 0.04$ \\
\hline 2 & 0 & $24.8 \pm 0.08$ \\
\hline 3 & $45.40 \pm 0.07$ & 0 \\
\hline 4 & 0 & 0 \\
\hline 5 & $20.13 \pm 0.04$ & 0 \\
\hline 6 & $46.98 \pm 0.06$ & 0 \\
\hline 7 & $23.44 \pm 0.04$ & 0 \\
\hline 8 & $76.58 \pm 0.07$ & 0 \\
\hline 9 & 0 & $27.9 \pm 0.07$ \\
\hline 10 & 0 & $9.04 \pm 0.04$ \\
\hline 11 & $193 \pm 0.21$ & $17.57 \pm 0.09$ \\
\hline 12 & $136 \pm 1.14$ & $26.28 \pm 0.08$ \\
\hline 13 & $18.27 \pm 0.04$ & 0 \\
\hline 14 & $44.03 \pm 0.09$ & 0 \\
\hline 15 & $21.04 \pm 0.04$ & 0 \\
\hline 16 & $117 \pm 0.14$ & 0 \\
\hline 17 & $35.98 \pm 0.09$ & $43.6 \pm 0.17$ \\
\hline 18 & $95.97 \pm 0.09$ & 0 \\
\hline 19 & $17.84 \pm 0.03$ & 0 \\
\hline 20 & $237 \pm 0.12$ & 0 \\
\hline 21 & $29.28 \pm 0.05$ & 0 \\
\hline 22 & $74.09 \pm 0.06$ & 0 \\
\hline 23 & $262 \pm 1.26$ & 0 \\
\hline 24 & $25.77 \pm 0.04$ & 0 \\
\hline
\end{tabular}

\begin{tabular}{|c|c|c|}
\hline \multirow{2}{*}{$\begin{array}{l}\text { No. of } \\
\text { urine } \\
\text { samples }\end{array}$} & \multicolumn{2}{|c|}{ Activity \pm Error (in $\mathbf{B q L}^{-1}$ ) } \\
\hline & $\begin{array}{c}{ }^{99 \mathrm{~m}} \mathrm{Tc} \\
(140.47 \mathrm{Kev})\end{array}$ & $\begin{array}{c}{ }^{131} \mathrm{I} \\
\text { (364.48Kev) } \\
\end{array}$ \\
\hline 25 & $109 \pm 0.04$ & $20.56 \pm 0.10$ \\
\hline 26 & $33.49 \pm 0.05$ & $21.07 \pm 0.06$ \\
\hline 27 & $314 \pm 1.92$ & 0 \\
\hline 28 & 0 & 0 \\
\hline 29 & $291 \pm 0.17$ & 0 \\
\hline 30 & 0 & 0 \\
\hline 31 & $39.88 \pm 0.06$ & $94.88 \pm 0.15$ \\
\hline 32 & $94.79 \pm 0.67$ & $106 \pm 0.16$ \\
\hline 33 & $15.69 \pm 0.04$ & $107 \pm 0.17$ \\
\hline 34 & $17.23 \pm 0.04$ & $87.95 \pm 0.15$ \\
\hline 35 & $46.01 \pm 0.04$ & $283 \pm 0.27$ \\
\hline 36 & $52.65 \pm 0.12$ & $198 \pm 1.73$ \\
\hline 37 & $301 \pm 0.17$ & $112 \pm 0.16$ \\
\hline 38 & $129 \pm 0.10$ & $181 \pm 1.64$ \\
\hline 39 & $22.98 \pm 0.06$ & $45.78 \pm 0.14$ \\
\hline 40 & 0 & $12.86 \pm 0.05$ \\
\hline 41 & $22.41 \pm 0.06$ & $29.15 \pm 0.10$ \\
\hline 42 & $10.57 \pm 0.04$ & $31.97 \pm 0.10$ \\
\hline 43 & $41.82 \pm 0.08$ & $41.70 \pm 0.04$ \\
\hline 44 & $29.31 \pm 0.05$ & $6.47 \pm 0.03$ \\
\hline 45 & 0 & $21.43 \pm 0.07$ \\
\hline 46 & 0 & $73.63 \pm 0.13$ \\
\hline 47 & $17.74 \pm 0.05$ & $52.01 \pm 0.15$ \\
\hline 48 & 0 & 0 \\
\hline 49 & 0 & 0 \\
\hline
\end{tabular}




\section{${ }^{99} \mathrm{~m}$ Tc and ${ }^{131} \mathrm{I}$ concentrations in urine samples}

The concentration of ${ }^{99 \mathrm{~m}} \mathrm{Tc}$ and ${ }^{131} \mathrm{I}$ in urine samples of occupational staff can be seen from Table 1 . The highest and the lowest detected radioactivity concentrations of ${ }^{99 \mathrm{~m}} \mathrm{Tc}$ in urine samples were $314 \pm 1.92 \mathrm{Bql}^{-1}$ and $8.58 \pm 0.03 \mathrm{Bql}^{-1}$ respectively, whereas the highest and lowest detected radioactivity concentrations of ${ }^{131} \mathrm{I}$ in urine samples were $283 \pm 0.27 \mathrm{Bql}^{-1}$ and $6.47 \pm 0.03 \mathrm{Bql}^{-1}$ respectively. These values were recorded from the female staff. For the male staff the highest detected radioactivity concentrations of ${ }^{99 \mathrm{~m}} \mathrm{Tc}$ and ${ }^{131} \mathrm{I}$ in urine samples were $291 \pm 0.17 \mathrm{Bql}^{-1}$ and $198 \pm 1.73$ $\mathrm{Bql}^{-1}$ respectively. On the other hand the lowest detected radioactivity concentrations were $18.27 \pm 0.04 \mathrm{Bql}^{-1}$ and $12.86 \pm 0.05 \mathrm{BqL}^{-1}$ respectively. Both the concentrations of ${ }^{131} \mathrm{I}$ and ${ }^{99 \mathrm{~m}} \mathrm{Tc}$ were detected in 20 urine samples because both isotopes were handled in the same area. So the subjects were internally exposed by inhalation of ${ }^{131} \mathrm{I}$ and contamination of ${ }^{99 \mathrm{~m}} \mathrm{Tc}$. It was inferred that the staff with ${ }^{131}$ I concentration in urine might inhale ${ }^{131}$ I radionuclide which was diffused into the air because of its volatile nature, during the distribution job of ${ }^{131} \mathrm{I}$. The probable reason for ${ }^{99 \mathrm{~m}} \mathrm{Tc}$ concentration in urine is due to contamination in the workplace.

The arithmetic mean of ${ }^{131} \mathrm{I}$ concentration of nuclear medicine staff in Korea was reported to be 66.5 $\pm 262 \mathrm{Bql}^{-1}$ [1]. The concentration ranged from 'Not detected' to $5045 \mathrm{Bql}^{-1}$. The arithmetic mean of

${ }^{131} \mathrm{I}$ concentration of nuclear medicine staff in Bangladesh is $34.39 \pm 58.79 \mathrm{Bql}^{-1}$. We can see that the nuclear medicine staff in Bangladesh are at much less risk of radiation hazards compared to Korean nuclear medicine staff. Even though the radiation contamination by occupational staff is low in Bangladesh, continued vigilance should be maintained to try to minimize this concentration as much as possible.

\section{Internal Dose}

The effective dose of ${ }^{99 \mathrm{~m}} \mathrm{Tc}$ and ${ }^{131} \mathrm{I}$ in urine samples of occupational staff were calculated using equations (2) and (3). The result of committed effective dose of ${ }^{99 \mathrm{~m}} \mathrm{Tc}$ and ${ }^{131} \mathrm{I}$ in urine samples of occupational staff is given in Table 2 .

Table 2: Effective Doses of occupational staff due to Intake of ${ }^{99 \mathrm{~m}} \mathrm{Tc}$ and ${ }^{131} \mathrm{I}$.

\begin{tabular}{|c|c|c|}
\hline $\begin{array}{l}\text { Name } \\
\text { of } \\
\text { Occupa } \\
\text { tional } \\
\text { staff }\end{array}$ & $\begin{array}{c}\text { Effective Dose } \\
(\mu \mathrm{Sv}) \text { due to } \\
{ }_{99 \mathrm{~m}} \mathrm{Tc}\end{array}$ & $\begin{array}{c}\text { Effective Dose } \\
(\mu \mathrm{Sv}) \text { due to } \\
{ }_{131} \mathrm{I}\end{array}$ \\
\hline \multirow{11}{*}{ A } & 4.02E-01 & $1.87 \mathrm{E}-01$ \\
\hline & $9.43 \mathrm{E}-01$ & - \\
\hline & - & $1.78 \mathrm{E}-01$ \\
\hline & $9.86 \mathrm{E}-01$ & - \\
\hline & 8.36E-01 & - \\
\hline & $4.44 \mathrm{E}+00$ & $2.10 \mathrm{E}+00$ \\
\hline & $2.16 \mathrm{E}+00$ & $5.58 \mathrm{E}+00$ \\
\hline & $1.47 \mathrm{E}+01$ & $2.20 \mathrm{E}+00$ \\
\hline & 4.95E-01 & $6.29 \mathrm{E}-01$ \\
\hline & $1.37 \mathrm{E}+00$ & $1.27 \mathrm{E}-01$ \\
\hline & - & 4.22E-01 \\
\hline
\end{tabular}

\begin{tabular}{|c|c|c|}
\hline \multirow{4}{*}{} & - & $4.89 \mathrm{E}-01$ \\
\cline { 2 - 3 } & $1.69 \mathrm{E}+00$ & $8.59 \mathrm{E}-01$ \\
\cline { 2 - 3 } & $3.00 \mathrm{E}-01$ & - \\
\cline { 2 - 3 } & - & $2.53 \mathrm{E}-01$ \\
\hline \multirow{4}{*}{ C } & $2.13 \mathrm{E}+00$ & - \\
\cline { 2 - 3 } & $2.20 \mathrm{E}+00$ & - \\
\cline { 2 - 3 } & - & $5.50 \mathrm{E}-01$ \\
\hline \multirow{4}{*}{$D$} & $2.06 \mathrm{E}+00$ & - \\
\hline \multirow{4}{*}{} & $4.50 \mathrm{E}+00$ & - \\
\cline { 2 - 3 } & - & - \\
\cline { 2 - 3 } & $1.10 \mathrm{E}+00$ & - \\
\cline { 2 - 3 } & $1.11 \mathrm{E}+00$ & - \\
\cline { 2 - 3 } & $1.04 \mathrm{E}+01$ & $3.05 \mathrm{E}-01$ \\
\cline { 2 - 3 } & $5.13 \mathrm{E}+00$ & - \\
\cline { 2 - 3 } & $2.47 \mathrm{E}+00$ & \\
\hline
\end{tabular}




\begin{tabular}{|c|c|c|}
\hline $\begin{array}{c}\text { Name } \\
\text { of } \\
\text { Occupa } \\
\text { tional } \\
\text { staff }\end{array}$ & $\begin{array}{l}\text { Effective Dose } \\
\left(\underset{\left.\left.{ }_{99}\right)_{\mathrm{m}}\right) \text { due to }}{{ }^{2}}\right.\end{array}$ & $\begin{array}{c}\text { Effective Dose } \\
(\mu \mathrm{Sv}) \text { due to } \\
{ }^{131} \mathrm{I}\end{array}$ \\
\hline \multirow{4}{*}{$\mathrm{F}$} & $3.59 \mathrm{E}+00$ & - \\
\hline & $9.02 \mathrm{E}+00$ & $3.46 \mathrm{E}-01$ \\
\hline & $3.47 \mathrm{E}+00$ & - \\
\hline & $1.57 \mathrm{E}+00$ & 4.15E-01 \\
\hline $\mathrm{G}$ & $6.37 \mathrm{E}+00$ & $5.17 \mathrm{E}-01$ \\
\hline $\mathrm{H}$ & $8.56 \mathrm{E}-01$ & - \\
\hline \multirow[t]{4}{*}{ I } & $5.50 \mathrm{E}+00$ & - \\
\hline & $1.08 \mathrm{E}+00$ & $9.01 \mathrm{E}-01$ \\
\hline & $1.05 \mathrm{E}+00$ & $5.74 \mathrm{E}-01$ \\
\hline & 8.31E-01 & $1.02 \mathrm{E}+00$ \\
\hline
\end{tabular}

\begin{tabular}{|c|c|c|}
\hline \multirow{2}{*}{ J } & $1.37 \mathrm{E}+00$ & - \\
\cline { 2 - 3 } & $1.47 \mathrm{E}+01$ & - \\
\hline $\mathrm{L}$ & - & - \\
\hline $\mathrm{M}$ & $1.36 \mathrm{E}+01$ & $1.87 \mathrm{E}+00$ \\
\hline N & $1.87 \mathrm{E}+00$ & $2.12 \mathrm{E}+00$ \\
\hline O & $7.31 \mathrm{E}-01$ & $1.73 \mathrm{E}+00$ \\
\hline P & $6.06 \mathrm{E}+00$ & $9.01 \mathrm{E}-01$ \\
\hline \multirow{2}{*}{$Q$} & $1.96 \mathrm{E}+00$ & $8.21 \mathrm{E}-01$ \\
\cline { 2 - 3 } & - & - \\
\hline \multirow{2}{*}{$R$} & - & $1.45 \mathrm{E}+00$ \\
\cline { 2 - 3 } & - & - \\
\hline \multirow{2}{*}{$S$} & - & - \\
\hline
\end{tabular}

Due to contamination of ${ }^{99 \mathrm{~m}} \mathrm{Tc}$, the highest effective dose; $14.7 \mu \mathrm{Sv}$ and the lowest effective dose; $0.402 \mu \mathrm{Sv}$, was that of staff $\mathrm{A}$. On the other hand, the highest effective dose, $5.58 \mu \mathrm{Sv}$ and the lowest effective dose, $0.12 \mu \mathrm{Sv}$, was that of staff A due to intake of ${ }^{131} \mathrm{I}$. The effective doses of occupational staff due to inhalation and contamination of ${ }^{131} \mathrm{I}$ and ${ }^{99 \mathrm{~m}} \mathrm{Tc}$ radionuclides were found low in comparison with annual effective dose of an occupational staff which is $20 \mathrm{mSv}$. The results of concentrations and doses can contribute to improving through regulations and deciding the radiological policies for the internal dosimetry of the radiation staff handling the radioisotopes in the medical fields.

\section{CONCLUSIONS}

Quantitatively evaluating the internal doses expected under the tasks related to the handling of ${ }^{99 \mathrm{~m}} \mathrm{Tc}$ and ${ }^{131} \mathrm{I}$ by the radiation staff is essential for ensuring their health. For internal radiation monitoring, 49 urine samples of 19 occupational staff were collected from two selected Nuclear Medicine Centers. These urine samples were analyzed to find the radioactivity of ${ }^{99 \mathrm{~m}} \mathrm{Tc}$ and ${ }^{131} \mathrm{I}$ using HPGe detector coupled to a Multichannel Analyzer (MCA) provided by Health Physics Division, Atomic Energy Centre, Dhaka under Bangladesh Atomic Energy Commission. After analyzing the samples, radioactivity concentrations were detected in 44 urine samples out of 49 , radioactivity concentrations of ${ }^{99 \mathrm{~m}} \mathrm{Tc}$ and ${ }^{131} \mathrm{I}$ were not found in 5 samples. The measured activity was then used to calculate the effective doses due to the intake of the radionuclides. The highest detected radioactivity concentrations of ${ }^{99 \mathrm{~m}} \mathrm{Tc}$ and ${ }^{131} \mathrm{I}$ in urine samples were $314 \pm 1.92 \mathrm{Bql}^{-1}$ and $283 \pm 0.27 \mathrm{Bql}^{-1}$ respectively. The lowest detected radioactivity concentrations of ${ }^{99 \mathrm{~m}} \mathrm{Tc}$ and ${ }^{131} \mathrm{I}$ in urine samples were $8.58 \pm 0.03 \mathrm{Bql}^{-1}$ and $6.47 \pm 0.03 \mathrm{Bql}^{-1}$ respectively. The highest $\left(314 \mathrm{Bql}^{-1}\right)$ and the lowest $\left(8.58 \mathrm{Bql}^{-1}\right)$ concentration of ${ }^{99 \mathrm{~m}} \mathrm{Tc}$ equivalent to the effective doses of $14.7 \mu \mathrm{Sv}$ and $0.402 \mu \mathrm{Sv}$ respectively, on the other hand for the highest $\left(283 \mathrm{Bql}^{-1}\right)$ and the lowest $\left(6.47 \mathrm{Bql}^{-1}\right)$ concentration of ${ }^{131} \mathrm{I}$, the effective doses were $5.58 \mu \mathrm{Sv}$ and $0.12 \mu \mathrm{Sv}$ respectively.

The experimental results showed that the internal monitoring are very useful for checking radiation risk of staff working with unsealed radioactive sources, in particular, for the case of inhalation of ${ }^{131} \mathrm{I}$ and contamination of ${ }^{99 \mathrm{~m}} \mathrm{Tc}$. The results of these measurements can contribute to improving the regulations and deciding the radiological policies for internal dosimetry of radiation staff handling the radioisotopes in the nuclear medicine fields. 
This study also showed that the arithmetic mean of ${ }^{131}$ I concentration of nuclear medicine staff in Bangladesh is $34.39 \pm 58.79 \mathrm{Bql}^{-1}$ which is much less than that of Korean nuclear medicine staff at $66.5 \pm 262 \mathrm{Bql}^{-1}$. This shows that the nuclear medicine staff in Bangladesh are not in risk of radiation hazards compared to Korean nuclear medicine staff. Even though the ${ }^{131}$ I concentration in urine of nuclear medicine staff in Bangladesh is low, the occupational staff in nuclear medicine practices of Bangladesh should try to keep this concentration as low as possible. Proper working environment should be established such as suitable ventilation system, fume hood and mask to avoid inhalation and contamination of ${ }^{131} \mathrm{I}$ and ${ }^{99 \mathrm{~m}} \mathrm{Tc}$. Finally, this study can be expanded to a basic one for guaranteeing the reliability for the results of internal doses for handling of ${ }^{131} \mathrm{I}$ and ${ }^{99 \mathrm{~m}} \mathrm{Tc}$.

\section{REFERENCES}

1. Dantas BM, Lucena EA; Dantas ALA, Internal exposure in nuclear medicine: Application of IAEA Criteria to Determine the Need for Internal Monitoring, Braz. arch. biol. technol. Vol.51 No. Spe Curitiba Dec. 2008,.

2. Lucena EA, Rebelo AMO, Araújo F, Sousa WO, Dantas ALA, Dantas BM and Corbo R., Evaluation of Internal Exposure of Nuclear Medicine Worker through in vivo and in vitro Bioassay Techniques, Radiation Protection Dosimetry127 (1-4): 465-468, 2007, doi: 10.1093/rpd/ncm365.

3. MODEL-ORTEC 495, Operating and Service Manual.

4. Iqubal SM, Calculation of Radiation Doses from Intake of Radionuclides. PhD thesis, National University Gazipur, 2011.

5. International Commission on Radiological Protection, Age-dependent Doses to Members of the Public from Intake of Radionuclides: Part 4 Inhalation Dose Coefficients, ICRP Publication, Pergamon Press, 71, 1995.

6. International Commission on Radiological Protection, Individual monitoring for internal exposure of workers, ICRP Publication, Pergamon Press, 78, 1997. 
